\title{
Prevalence and determinants of risky sexual practice in Ethiopia: Systematic review and Meta-analysis
}

\author{
Achenef Asmamaw Muche ${ }^{1 *}$, Getachew Mullu Kassa², Abadi Kidanemariam Berhe ${ }^{3}$ and Gedefaw Abeje Fekadu ${ }^{4}$
}

\begin{abstract}
Background: Risky sexual practice is a major public health problem in Ethiopia. There are various studies on the prevalence and determinants of risky sexual practice in different regions of the country but there is no study which shows the national estimate of risky sexual practices in Ethiopia. Therefore, this review was conducted to estimate the national pooled prevalence of risky sexual practice and its risk factors in Ethiopia.

Methods: The Preferred Reporting Items for Systematic Reviews and Meta-Analyses guideline was followed to review published and unpublished studies in Ethiopia. The databases used were; PubMed, Google Scholar, CINAHL and African Journals Online. Search terms were; risky sexual behavior, risky sexual practice, unprotected sex, multiple sexual partner, early sexual initiation, and/or Ethiopia. Joanna Briggs Institute Meta-Analysis of Statistics Assessment and Review Instrument was used for critical appraisal. The meta-analysis was conducted using Review Manager software. Descriptive information of studies was presented in narrative form and quantitative results were presented in forest plots. The Cochran $Q$ test and $P$ test statistics were used to test heterogeneity across studies. The pooled estimate prevalence and the odd ratios with $95 \%$ confidence intervals were computed by a random effect model.
\end{abstract}

Results: A total of 31 studies with 43,695 participants were included in the meta-analysis. The pooled prevalence of risky sexual practice was 42.80\% (95\% Cl: 35.64\%, 49.96\%). Being male (OR: 1.69; 95\% Cl: 1.21, 2.37), substance use (OR: 3.42; 95\% Cl: 1.41, 8.31), peer pressure (OR: 3.41; 95\% Cl: 1.69, 6.87) and watching pornography (OR: 3.6; 95\% Cl: $2.21,5.86)$ were factors associated with an increase in risky sexual practices.

Conclusions: The prevalence of risky sexual practices is high in Ethiopia. Being male, substance use, peer pressure and viewing pornographic materials were found to be associated with risky sexual practices. Therefore, life skills training is recommended to reduce peer pressure among individuals. Interventions should be designed to reduce substance use and viewing pornography.

Keywords: Risky sexual practices, Peer pressure, Substance use, Pornography, Gender, Ethiopia, Systemic review, Meta-analysis

\section{Plain English summary}

Risky sexual practices increase the likelihood of sexually transmitted infections, unintended pregnancies and unsafe abortion. Ethiopia is one of the sub-Saharan countries with a high burden of sexual and reproductive health problems, risky sexual practices increase this burden. The prevalence of

\footnotetext{
* Correspondence: ashua2014@gmail.com

${ }^{1}$ Department of Epidemiology and Biostatistics, Institute of Public Health,

University of Gondar, Gondar, Ethiopia

Full list of author information is available at the end of the article
}

risky sexual practices varies from place to place in Ethiopia. Poor knowledge of sexual and reproductive health services, peer pressure, substance use and poverty are factors associated with risky sexual practices.

There were several studies on prevalence and determinants of risky sexual practices in Ethiopia; however, none show the magnitude and determinants at the national level. Therefore, this review was conducted to identify the prevalence and determinants of risky sexual practices in Ethiopia. Thirty-one 
articles with 43,695 participants were included. The review identified risky sexual practice as a common public health problem in Ethiopia. About $43 \%$ of the participants reported being involved in risky sexual practice. In this review, males were more likely to engage in risky sexual practices than females. Substances users were also more likely to engage in risky sexual practices. Individuals who reported the influence of others to reach decision were more likely to engage in risky sexual practices. Similarly, people who reported viewing pornography were more likely to engage in risky sexual practices. Therefore, governmental and non-governmental organizations should work to address the identified determinant factors to reduce the high burden of risky sexual practice.

\section{Background}

Risky sexual behavior is defined as any sexual activity that increases the risk of contracting sexually transmitted infections (STI) and unintended pregnancies. It includes having sex with multiple sexual partners, not using or inconsistent condom use, sex under the influence of substances and initiation of sex before the age of 18 years. An individual is considered as engaging in risky sexual practice if she/he experienced one or more of the above behaviors [1].

Risky sexual practices increase the risk of HIV/ AIDS, unintended pregnancy, unsafe abortion and psychosocial problems [2]. These problems can be aggravated by low income, job insecurity, lack of awareness about sexual and reproductive health issues and harmful traditional practices [3].

Studies showed that poor knowledge of sexual and reproductive health services, peer pressure, substance use, low economic conditions, and poor supervision by parents are factors which can lead to risky sexual practices [4, 5]. Additionally, globalization, curiosity, and enthusiasm of persons to try new things, especially young people, increase risky sexual practices [5].

The Ethiopian government has developed and implemented various strategies to promote sexual and reproductive health [6]. Despite these interventions, different studies in the country showed a high prevalence of risky sexual practices. This level ranges from $13 \%$ in Humera to $27 \%$ in Addis Ababa [7-9]. These studies showed inconsistent findings of the prevalence of risky sexual practices. Therefore, this study was conducted to summarize the current evidence on the prevalence and determinants of risky sexual practices in Ethiopia.

\section{Methods}

\section{Study design and search strategy}

A systemic review and meta-analysis was conducted using published and unpublished research on the prevalence of risky sexual practices and its associated factors in Ethiopia. All relevant published studies in the following major databases; PubMed, Google scholar, CINAHL, and African Journals Online were included in the review. All published and unpublished articles up to December 30, 2016 were included in the review. The reference lists of identified studies were also reviewed to retrieve additional articles. Unpublished studies were retrieved from the official website of Addis Ababa University electronic database [10]. The following search terms were used: risky sexual practice, multiple sexual partners, commercial sex worker, early sexual initiation, premarital sex, inconsistent use of condom, unprotected sexual activity, sex under the influence of substances, sex with commercial sex workers and Ethiopia separately and/or in combination. The Preferred Reporting Items for Systematic Reviews and Meta-Analyses (PRISMA) guideline was followed during the systematic review [11].

\section{Study selection and eligibility criteria}

The following criteria were used to determine the eligibility of studies.

\section{Inclusion criteria:}

- Participants: this review included studies that were conducted on risky sexual practices and its determinants in Ethiopia. The participants were people of all ages regardless of their sex and occupation.

- Setting: Studies conducted at community or institutional level in Ethiopia.

- Outcome: The prevalence of risky sexual practices using the communicable disease control (CDC) definition [1].

- Type of study: All study types were included in the review.

- Publication types: journal articles, master's thesis and dissertations

- Only studies in English were included in the review.

\section{Exclusion criteria:}

- Studies with the methodological problems and review articles were excluded from the review.

- Retrieved articles were assessed for inclusion using their title, abstract and then a full-text review of articles for quality was done before inclusion in the final review. 


\section{Data extraction}

The data extraction was done by four researchers using a data extraction tool. This tool included information on the title, author, year of survey and publication, study design, sample size, data collection procedure, study participants, study area, response rate, sampling method and the definition used for risky sexual practices.

\section{Quality assessment and data collection}

The Joanna Briggs Institute Meta-Analysis of Statistics Assessment and Review Instrument (JBI-MAStARI) was used for critical appraisal [12]. This tool contains a separate appraisal checklist for each type of the study design. Two reviewers independently assessed articles prior to inclusion in the final review using this instrument. Any disagreement which arose between the reviewers was resolved through discussion, and by involving a third reviewer. Studies with quality assessment score of $50 \%$ and above and studies having a response rate of $80 \%$ and above were included in the final review.

\section{Publication bias and heterogeneity}

Publication bias and heterogeneity were assessed. To check the publication bias, a funnel plot was used. The distribution of studies and a $p$-value $<0.05$ were used to declare publication bias. The heterogeneity of studies was checked using Q test and $I^{2}$ test statistics. $I^{2}$ test statistics results of $25 \%, 50 \%$, and $75 \%$ were declared as low, moderate and high heterogeneity respectively. For the test result, which indicates the presence of heterogeneity, a random effects model was used for analysis.

\section{Statistical methods and analysis}

The meta-analysis was conducted using Review Manager (RevMan) software version 5.3. Forest plots were used to present the combined estimate with $95 \%$ confidence intervals (CI). For studies which did not present a standard error (SE), it was calculated using the formula; $\mathrm{SE}=$ $\sqrt{ } \mathrm{p} \times(1-\mathrm{p}) / \mathrm{n}$ in Microsoft excel. The calculated standard error and prevalence rate of each study was then entered into RevMan software to calculate the overall prevalence and its 95\% CI. Subgroup analyses were conducted based on the gender, substance use, peer pressure and viewing pornography on the risky sexual practices of study participants.

\section{Results}

\section{Study selection}

The review found a total of 1120 published articles and 10 unpublished reports. From this, 102 duplicate records were removed and 977 records were excluded after screening by title and abstract. A total of 51 full-text articles were screened for eligibility. From this, 20 articles were excluded since they failed to fulfill the eligibility or quality criteria. Finally, 31 studies were included in the analysis (Fig. 1).

\section{Characteristics of included studies}

All included articles were cross-sectional studies. Four of the included studies were unpublished [13-16]. The sample size of studies ranged from a minimum of 236, a study conducted among youth in Dilla town, Southern Ethiopia [17] to a maximum of 20,434, a nationwide study [18]. A total of 43,695 participants were included in the review. The studies were conducted from 2001 to 2016 in different regions of the country (Table 1).

\section{Prevalence of risky sexual practice in Ethiopia}

The highest prevalence of risky sexual practice was reported in a study among in-school youth in Debre Markos town, Northwest Ethiopia. The study showed that $78.8 \%$ initiated sex at an early age ( $<18$ years) $[13]$. The lowest prevalence of risky sexual practice was $10.6 \%$ among school adolescents in Addis Ababa, Ethiopia [19].

As presented in Fig. 2, the $I^{2}$ test result showed high heterogeneity $\left(\mathrm{I}^{2=} 100 \%\right)$, which is indicative of using random effects model. The overall pooled prevalence of risky sexual practice in Ethiopia was $42.8 \%$ (95\% CI: 35.64\%, 49.96\%) (Fig. 2).

\section{Gender disparity and risky sexual practice}

A total of 14 articles with 25,887 participants were included to assess the association of gender and risky sexual practices [13-16, 18, 20-28]. The findings showed a higher prevalence of risky sexual practice among males (73.24\%) compared to females (70.16\%). There was a significant association between gender and risky sexual practices. Males were 1.69 times more likely to engage in risky sexual practices compared to females (OR: 1.69, 95\% CI: 1.21, 2.37) (Fig. 3).

\section{Substance use and risky sexual practice}

A total of 16 articles with 26,257 participants were included to identify the association between substance use and risky sexual practices [13-16, 18, 20-22, 24-31]. Substance users were 3.4 times more likely engage in risky sexual practices compared to nonusers (OR: 3.42; 95\% CI: 1.41, 8.31) (Fig. 4).

\section{Peer pressure and risky sexual practice}

Ten articles with a total of 8486 participants were included in the analysis $[14,16,19-22,24,25,29,32]$. Individuals who reported to be influenced by peers for their risky sexual practice were 3.4 times more likely to engage in risky sexual practices (OR: 3.41: 95\% CI: 1.69, 6.87) (Fig. 5). 


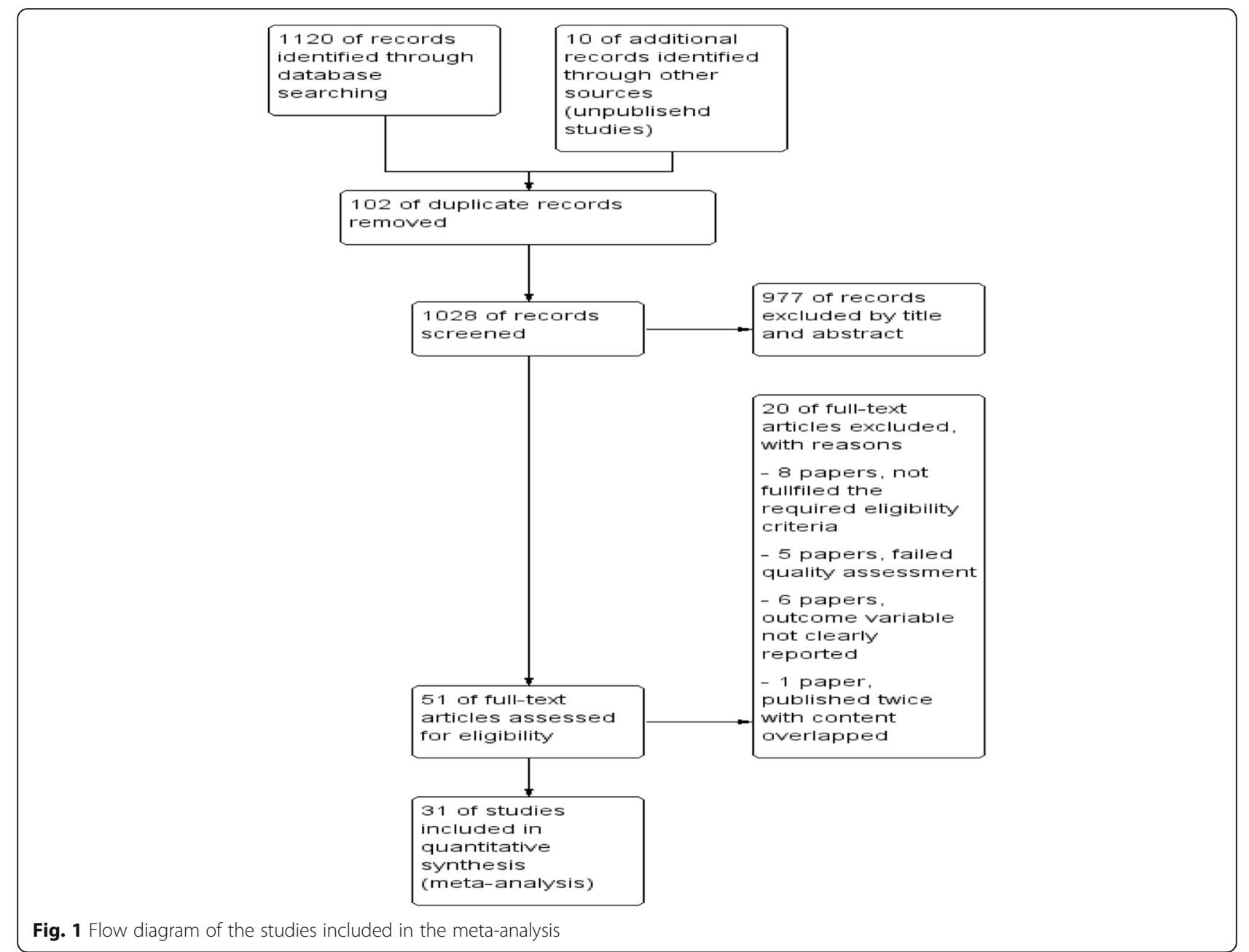

\section{Viewing pornography and risky sexual practices}

Nine articles with a total of 4585 participants were included in this analysis [13, 16, 20, 21, 24, 27-30]. There was a higher prevalence of risky sexual practices among participants who viewed pornography (50.27\%) compared to those who did not (27.66\%). Risky sexual practices were four times more likely to occur among participants who viewed pornography (OR: 3.6: 95\% CI: 2.21, 5.86) (Fig. 6).

\section{Discussion}

This review was conducted to identify the prevalence of risky sexual practices and its associated factors in Ethiopia. The overall pooled prevalence of risky sexual practice in Ethiopia was $42.8 \%$ (95\% CI: 35.64\%, $49.96 \%)$. This finding was lower than the prevalence of risky sexual behavior (75\%) demonstrated among male youth in Latin America [37]. The differences in the findings may reflect differences in participants' characteristics. This review included both male and female participants, while the other study included only male participants. The other possible explanation could be the difference in the age of participants, this review included both adolescents and adults. On the other hand, the prevalence of risky sexual practice in this review was higher than a meta-analysis of high-risk sexual behavior of women in sub-Saharan countries [38]. The difference may be due to the variation in the study population and sociocultural differences, such as the freedom to talk about sexuality, sex out of marriage, multiple sexual partners and others.

The subgroup analysis of gender and risky sexual practice showed that males were 1.69 times more likely to engage in risky sexual practices compared to females. This finding is in line with a global study on risky sexual behavior using data from 59 countries which showed that risky sexual practices were higher among men than women [33]. The higher prevalence of risky sexual practice among men may 


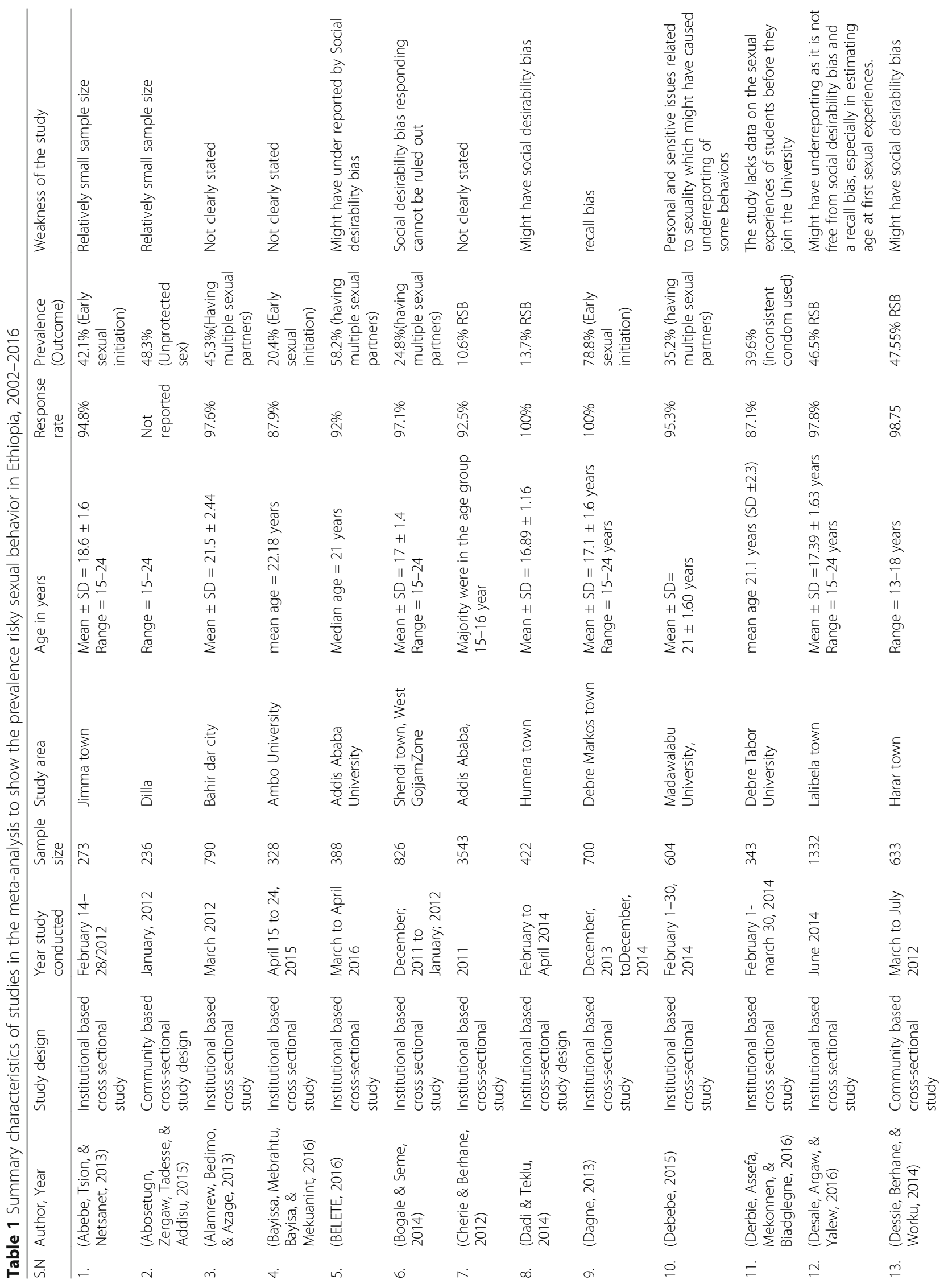




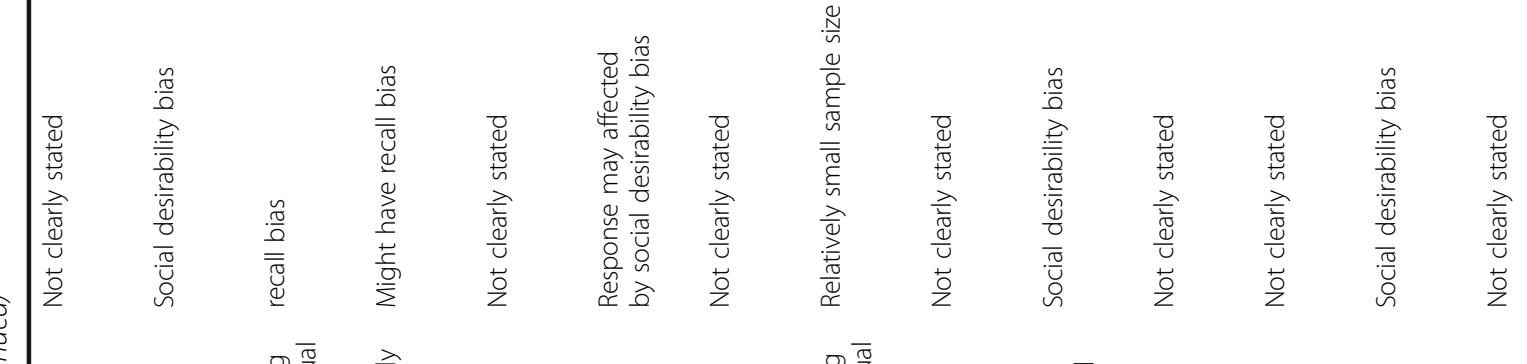

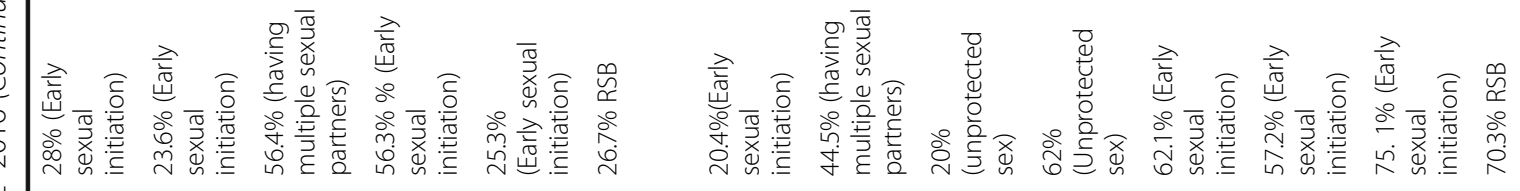
ธิ

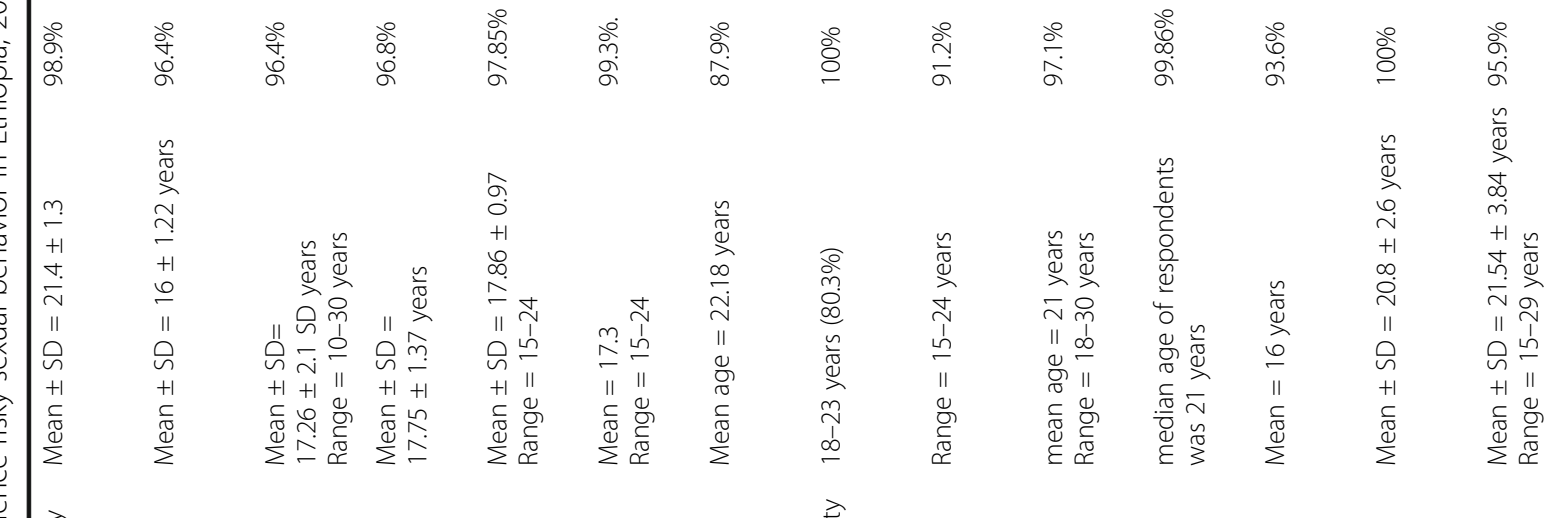

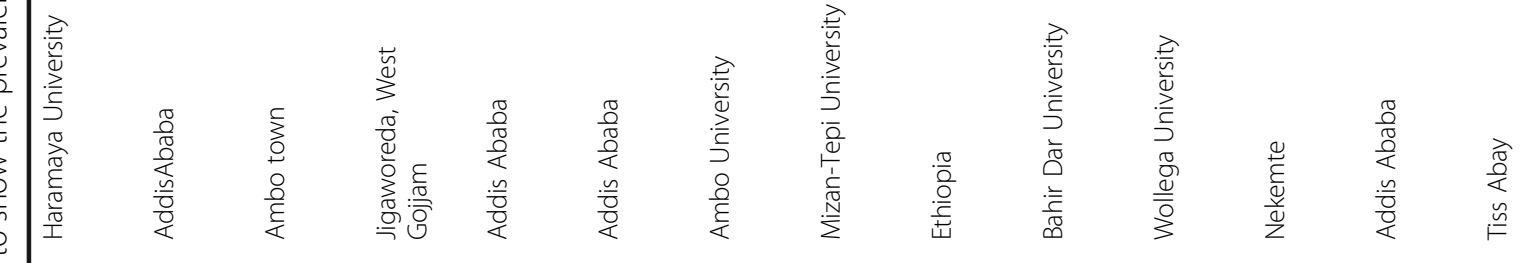

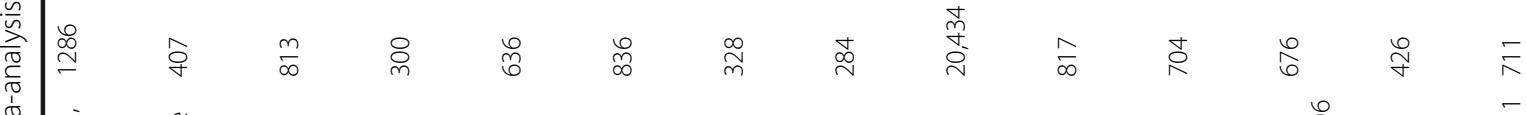

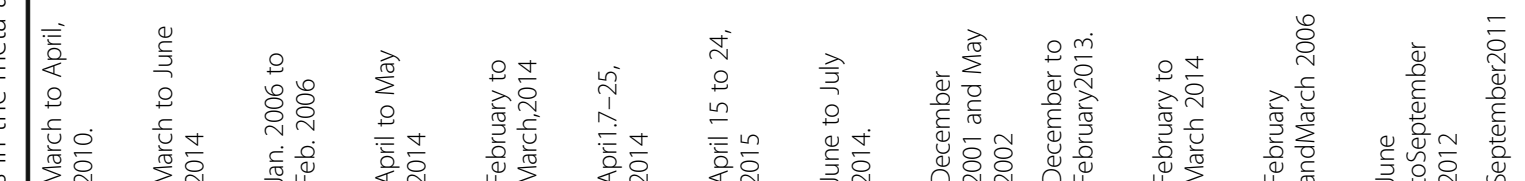
$\stackrel{\breve{c}}{\underline{0}}$

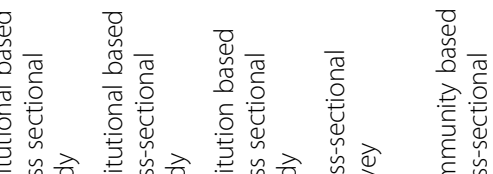




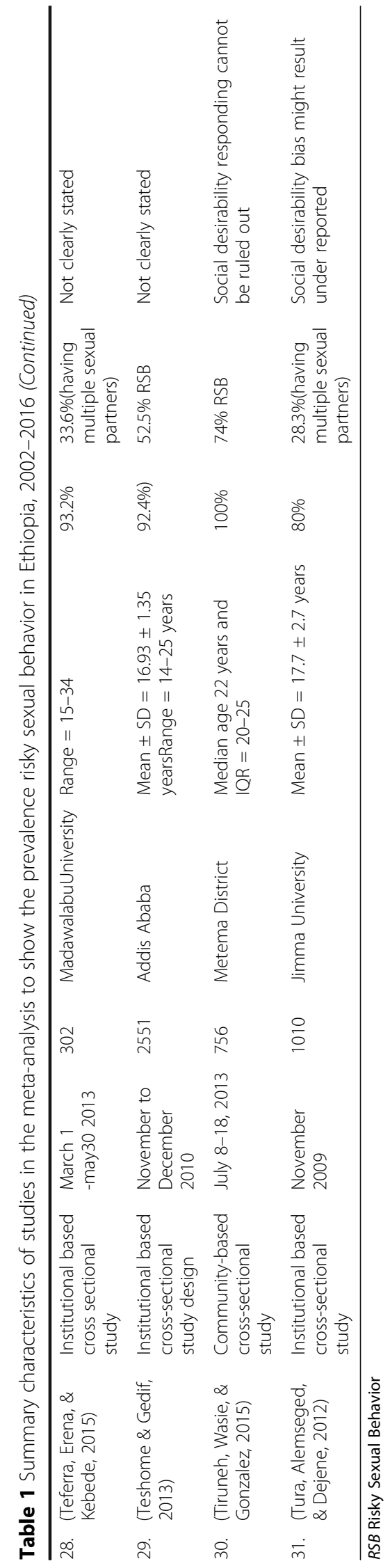




\begin{tabular}{|c|c|c|c|c|c|c|}
\hline Study or Subgroup & Prevalence of risky sexual behaviour & SE & \multicolumn{2}{|r|}{ Prevalence of risky sexual behaviour } & \multicolumn{2}{|c|}{$\begin{array}{l}\text { Prevalence of risky sexual behaviour } \\
\text { IV, Random, } 95 \% \mathrm{Cl}\end{array}$} \\
\hline (Abebe, Tsion, \& Netsanet, 2013) & 42.1 & 2.99 & $3.2 \%$ & $42.10[36.24,47.96]$ & & $\rightarrow$ \\
\hline (Abosetugn, Zergaw, Tadesse, \& Addisu, 2015) & 48.3 & 3.25 & $3.2 \%$ & $48.30[41.93,54.67]$ & & $\rightarrow$ \\
\hline (Alamrew, Bedimo, \& Azage, 2013) & 45.3 & 1.77 & $3.2 \%$ & $45.30[41.83,48.77]$ & & - \\
\hline (Bayissa, Mebrahtu, Bayisa, \& Mekuanint, 2016) & 20.4 & 2.23 & $3.2 \%$ & $20.40[16.03,24.77]$ & & $\rightarrow$ \\
\hline (BELETE, 2016) & 58.2 & 2.5 & $3.2 \%$ & $58.20[53.30,63.10]$ & & $\rightarrow$ \\
\hline (Bogale \& Seme, 2014) & 24.8 & 1.5 & $3.2 \%$ & $24.80[21.86,27.74]$ & & - \\
\hline (Cherie \& Berhane, 2012) & 10.6 & 0.52 & $3.3 \%$ & $10.60[9.58,11.62]$ & & - \\
\hline (Dadi \& Teklu, 2014) & 13.7 & 1.67 & $3.2 \%$ & $13.70[10.43,16.97]$ & & - \\
\hline (Dagne, 2013) & 78.8 & 1.54 & $3.2 \%$ & $78.80[75.78,81.82]$ & & \\
\hline (Debebe, 2015) & 35.2 & 1.94 & $3.2 \%$ & $35.20[31.40,39.00]$ & & $\rightarrow$ \\
\hline (Derbie, Assefa, Mekonnen, \& Biadglegne, 2016) & 39.6 & 2.64 & $3.2 \%$ & $39.60[34.43,44.77]$ & & $\rightarrow$ \\
\hline (Desale, Argaw, \& Yalew, 2016) & 46.5 & 1.37 & $3.2 \%$ & $46.50[43.81,49.19]$ & & - \\
\hline (Dessie, Berhane, \& Worku, 2014) & 47.55 & 1.98 & $3.2 \%$ & $47.55[43.67,51.43]$ & & - \\
\hline (Dingeta, Oljira, \& Assefa, 2012) & 28 & 1.25 & $3.2 \%$ & $28.00[25.55,30.45]$ & & - \\
\hline (Fite \& Cherie, 2016) & 23.6 & 2.1 & $3.2 \%$ & $23.60[19.48,27.72]$ & & $\rightarrow$ \\
\hline (Fury, 2006) & 56.4 & 1.74 & $3.2 \%$ & $56.40[52.99,59.81]$ & & $\rightarrow$ \\
\hline (G. M. Kassa et al. 2016) & 56.3 & 2.86 & $3.2 \%$ & $56.30[50.69,61.91]$ & & $\rightarrow$ \\
\hline (Girma, Hailu, Avana, \& Ketema, 2015) & 25.3 & 1.72 & $3.2 \%$ & $25.30[21.93,28.67]$ & & - \\
\hline (Gizaw, Jara, \& Ketema, 2014) & 26.7 & 1.53 & $3.2 \%$ & $26.70[23.70,29.70]$ & & - \\
\hline (Guta \& Yeshambel, 2016) & 20.4 & 2.23 & $3.2 \%$ & $20.40[16.03,24.77]$ & & $\rightarrow$ \\
\hline (Henok, Kassa, Lenda, Nibret, \& Lamaro, 2015) & 44.5 & 2.95 & $3.2 \%$ & $44.50[38.72,50.28]$ & & $\leftarrow$ \\
\hline (Kebede et al., 2005) & 20 & 0.28 & $3.3 \%$ & $20.00[19.45,20.55]$ & & - \\
\hline (Mulu, Yimer, \& Abera, 2014) & 62 & 1.7 & $3.2 \%$ & $62.00[58.67,65.33]$ & & - \\
\hline (Regassa, Chala, \& Adeba, 2016) & 62.1 & 1.83 & $3.2 \%$ & $62.10[58.51,65.69]$ & & - \\
\hline (Seme \& Wirtu, 2016) & 57.2 & 1.9 & $3.2 \%$ & $57.20[53.48,60.92]$ & & - \\
\hline (T. A. Kassa, Luck, Birru, \& Riedel-Heller, 2014) & 75.1 & 2.1 & $3.2 \%$ & $75.10[70.98,79.22]$ & & + \\
\hline (Tadesse \& Yakob, 2015) & 70.3 & 1.71 & $3.2 \%$ & $70.30[66.95,73.65]$ & & - \\
\hline (Teferra, Erena, \& Kebede, 2015) & 33.6 & 2.72 & $3.2 \%$ & $33.60[28.27,38.93]$ & & $\rightarrow$ \\
\hline (Teshome \& Gedif, 2013) & 52.5 & 0.99 & $3.2 \%$ & $52.50[50.56,54.44]$ & & - \\
\hline (Tiruneh, Wasie, \& Gonzalez, 2015) & 74 & 1.6 & $3.2 \%$ & $74.00[70.86,77.14]$ & & + \\
\hline (Tura, Alemseged, \& Dejene, 2012) & 28.3 & 1.42 & $3.2 \%$ & $28.30[25.52,31.08]$ & & + \\
\hline Total $(95 \% \mathrm{Cl})$ & & & $100.0 \%$ & $42.80[35.64,49.96]$ & & 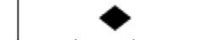 \\
\hline $\begin{array}{l}\text { Heterogeneity: Tau }{ }^{2}=409.67 ; \mathrm{Ch}^{2}=7681.01 \text {, df }= \\
\text { Test for overall effect: } Z=11.72(P \approx 0.00001)\end{array}$ & $30(P<0.00001) ; P^{2}=100 \%$ & & & & -50 & $\begin{array}{ccc} & 1 & 1 \\
0 & 25 & 50 \\
\text { Prevalence of RSB }\end{array}$ \\
\hline
\end{tabular}

be due to a higher proportion involved with multiple sexual partners and higher rate of substance use. The Global School-Based Student Health Survey (GSHS) conducted in Trinidad and Tobago showed that men were more likely to engage in premarital and early sex than women
[33]. A large-scale study conducted by Mid-western State University reported that men were more likely to engage in risky sexual practice compared to women [39]. Men are also more likely to have multiple sexual partners compared to women $[34,35]$.

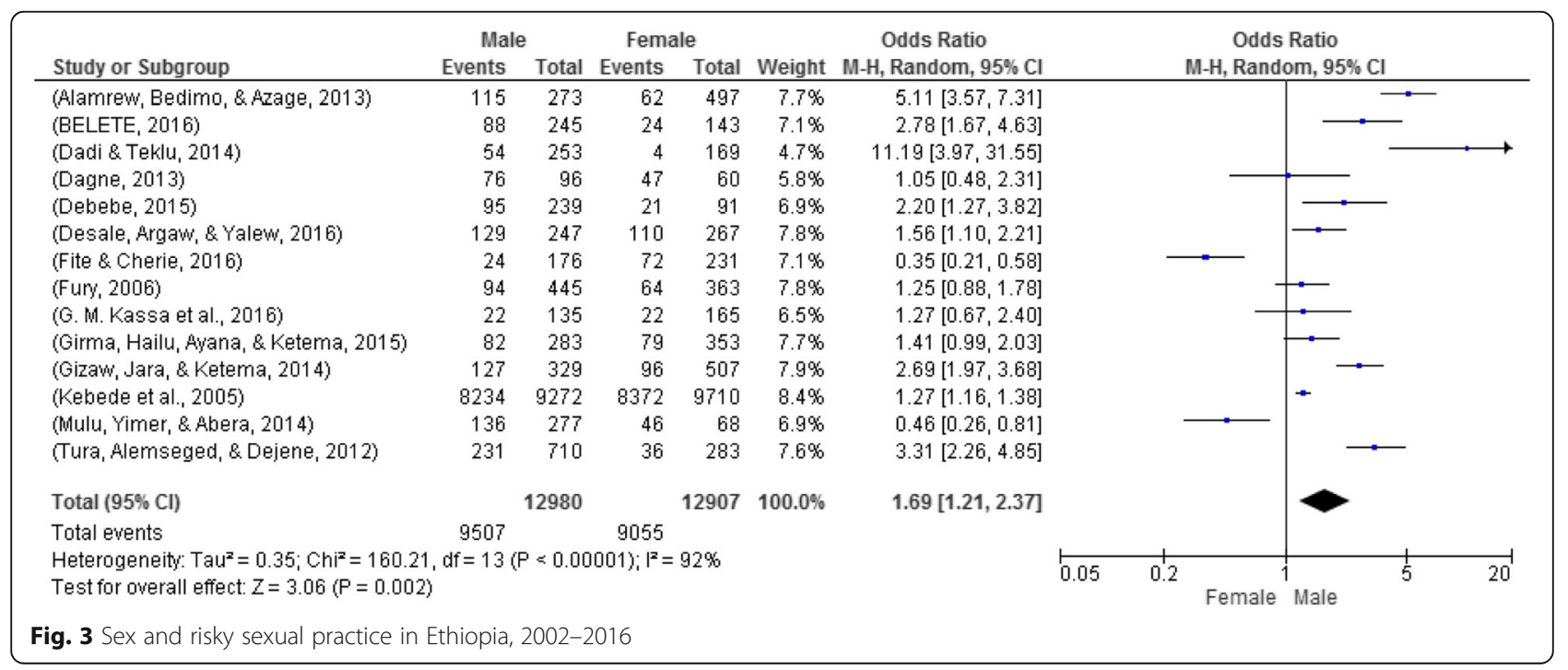




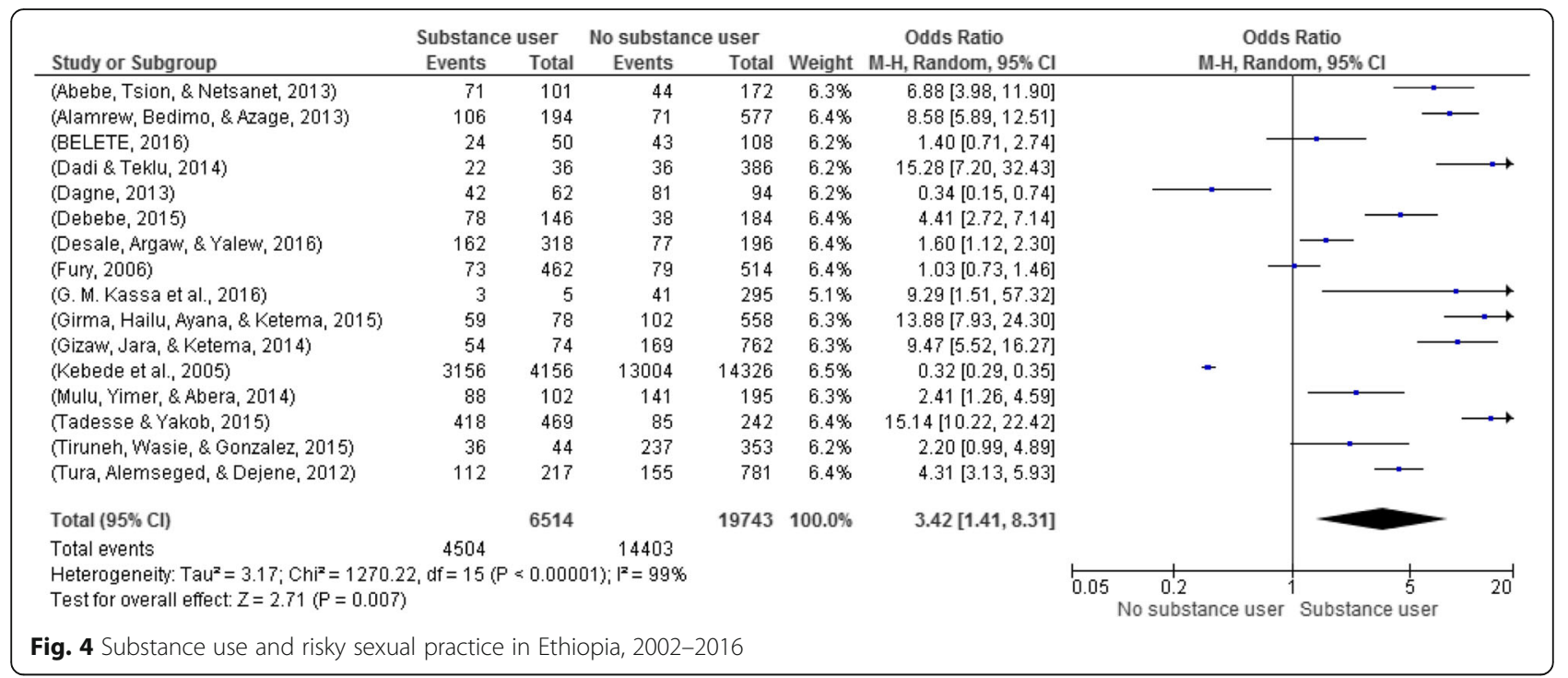

This review showed that substance users were more likely to engage the risky sexual practice. This finding was similar to studies conducted by WHO and UNAIDS in eight countries [36] and a meta-analysis conducted in Latin America [37]. The reason for this could be because alcohol use affects decision making which may lead to risky sexual practice.

This study identified peer pressure as an important predictor of risky sexual practice. This finding is in line with a study in Ghana and a meta-analysis conducted in sub-Saharan Africa [38, 39]. The reason for this may be that people do not want to be different or rejected, and they may engage in risky behaviors because of the pressure from friends; this may especially be true for youth.

This study also indicated that viewing pornography was associated with risky sexual practices. A population-based study in Sweden indicated that boys who viewed pornography were more likely to engage in risky sexual practices [40]. Individuals who viewed or read pornographic materials frequently were more likely to have multiple sexual partners compared to those who did not [41]. This might be due to the impulsive nature of pornographic materials which lead to erotic sex stimulation or risky sexual practices.

This review used a comprehensive search strategy and multiple database searches of both published and unpublished articles. Random effect model was used to address the issues of potential variability across studies. Included articles were restricted to English language only; this is a limitation of the study as it missed studies published in other languages. All studies included were cross sectional which cannot show a cause and effect relationship between risky sexual practice and the characteristics presented.

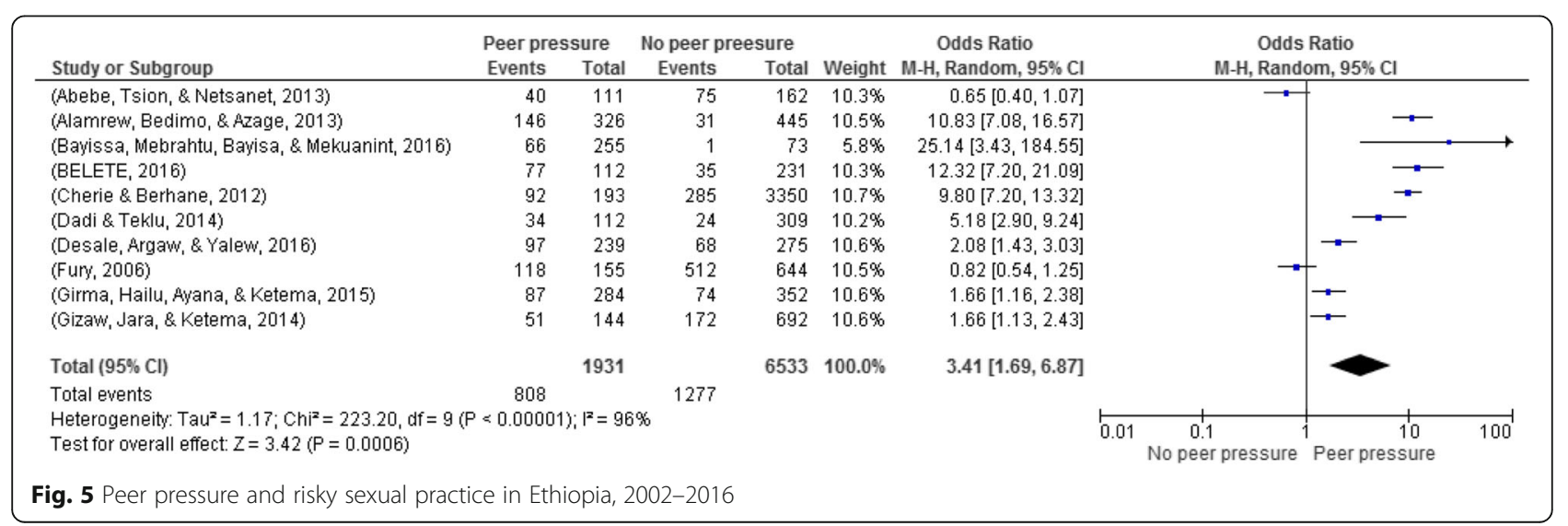




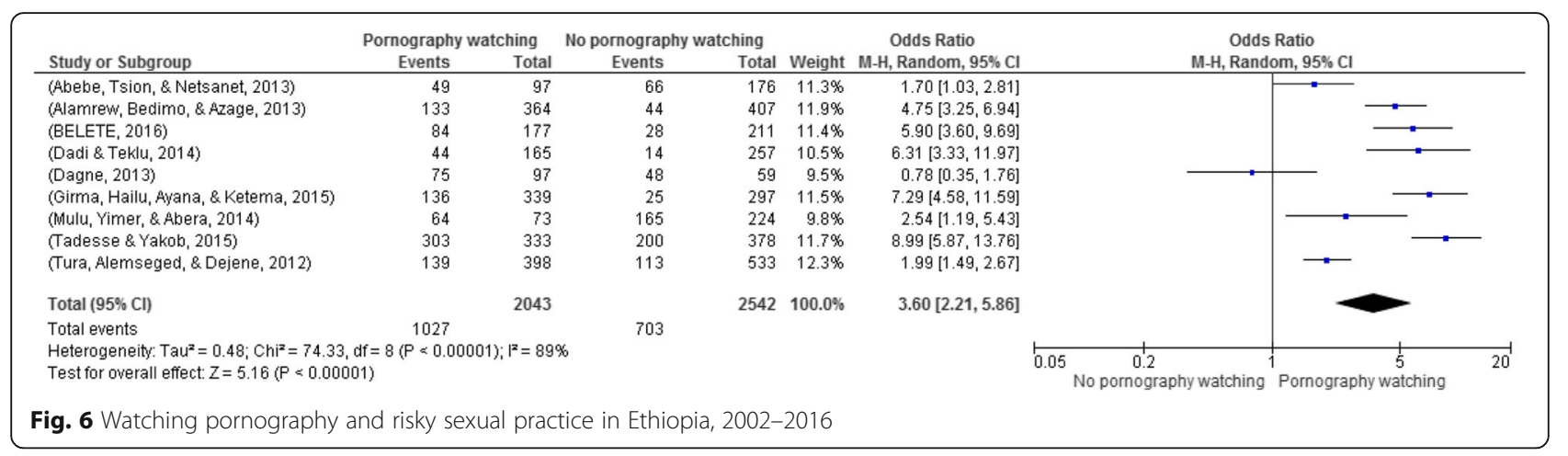

\section{Conclusion}

This systematic review and meta-analysis revealed that the prevalence of risky sexual practice was high in Ethiopia. Being male, substance use, peer pressure and viewing pornographic materials were found to be associated with risky sexual practices. Governments and relevant stakeholders should develop effective programs and interventions to address gender-specific communication and life skills to minimize risky sexual practices. Comprehensive multi-level behavioral interventional programs are needed to reduce peer pressure, substance use and watching pornography and formulating an appropriate strategy to monitor pornography and substance use. The authors recommend large-scale studies to identify other variables which could affect risky sexual practices in the country.

\section{Abbreviations}

AIDS: Acquired Immune Deficiency Syndrome; CINAHL: Cumulative Index to Nursing and Allied Health Literature; EDHS: Ethiopian Demographic and Health Survey; HIV: Human Immunodeficiency Virus; JBI-MAStARI: Joanna Briggs Institute Meta-Analysis of Statistics Assessment and Review Instrument; OR: Odds Ratio; PRISMA: Preferred Reporting Items for Systematic Reviews and Meta-Analyses; SD: Standard Deviation; USAID: United States Agency for International Development; WHO: World Health Organization

\section{Acknowledgements}

We would like to thank all authors of the research paper included in this systematic review and meta-analysis.

\section{Funding}

No funding was obtained for this study.

\section{Availability of data and materials}

All data pertaining to this study are contained and presented in this document.

\begin{abstract}
Authors' contributions
AAM involved in the design, selection of articles, data extraction, statistical analysis and manuscript writing. GMK, AKB and GAF also involved in data extraction, analysis and manuscript editing. All authors read and approved the final draft of the manuscript.
\end{abstract}

Ethics approval and consent to participate Not applicable.

\section{Consent for publication}

Not applicable.
Competing of interest

The authors declare no competing of interest.

\section{Publisher's Note}

Springer Nature remains neutral with regard to jurisdictional claims in published maps and institutional affiliations.

\section{Author details}

'Department of Epidemiology and Biostatistics, Institute of Public Health, University of Gondar, Gondar, Ethiopia. ${ }^{2}$ College of Health Sciences, Debre Markos University, Debre Markos, Ethiopia. ${ }^{3}$ College of Medicine and Health Sciences, Adigrat University, Adigrat, Tigray, Ethiopia. ${ }^{4}$ School of Public Health, College of Medicine and Health Sciences, Bahir Dar University, Bahir Dar, Ethiopia.

Received: 10 February 2017 Accepted: 1 September 2017 Published online: 06 September 2017

\section{References}

1. Eaton DK, Kann L, Kinchen S, Shanklin S, Ross J, Hawkins J, et al. Youth risk behavior surveillance-United States, 2009. Morbidity and mortality weekly report Surveillance summaries (Washington, DC: 2002). 2010;59(5):1-142.

2. Taylor-Seehafer M, Rew L. Risky sexual behavior among adolescent women. J Specialists Pediat Nursing. 2000;5(1):15-25.

3. Govindasamy P, Kidanu A, Bantayerga $H$. Youth reproductive health in Ethiopia: OCR macro; 2002

4. Victoria FP. The sexual and reproductive health of young Victorians: family planning Victoria, Royal Women's hospital, Royal Children's Hospital; 2005.

5. Blum RW, Mmari, Kristin Nelson,. Risk and protective factors affecting adolescent reproductive health in developing countries Geneva: Department of Population and Family Health Sciences, Johns Hopkins Bloomberg School of Public Health, 2005.

6. Federal Democratic Republic of Ethiopia Ministry of Health. National adolescent and youth reproductive health strategy: 2007-2015. Ethiopia: $\mathrm{MOH}$.

7. Dadi AF, Teklu FG. Risky sexual behavior and associated factors among grade 9-12 students in Humera secondary school, western zone of Tigray, Ethiopia. Science Journal of Public Health. 2014;2:410-6.

8. Agajie M, Belachew T, Tilahun T, Amentie M. Risky sexual behavior and associated factors among high school youth in Pawe Woreda, Benishangul Gumuz Region. Science Journal of Clinical Medicine. 2015;4(4):67-75.

9. Gizaw A, Jara D, Ketema K. Risky Sexual Practice and Associated Factors among High School Adolescent in Addis Ababa: Family Medicine \& Medical Science Research. 2014;3:141

10. Addis Ababa University Institutional Repository. Retrived on December 25/ 2016 from: http://etd.aau.edu.et/handle/123456789/1557 [Internet].

11. Moher D, Liberati A, Tetzlaff J, Altman DG. Preferred reporting items for systematic reviews and meta-analyses: the PRISMA statement. Ann Intern Med. 2009;151(4):264-9.

12. The Joanna Briggs Institute. Joanna Briggs institute reviewers' manual: 2008 .

13. Dagne B. Age at First sexual debut and condom use among in school youth in Debre Markos town, Amhara region. Unpublished MPH thesis, AAU, Ethiopia; 2013. 
14. Fury B. Assessment of premarital sexual practices and factors related to it among Ambo high school students. Unpublished MPH thesis, AAU, Ethiopia; 2006.

15. Debebe W. Sexual risk Behaviours and associated factors among undergraduate students in Madawalabu University, South East Ethiopia. Unpublished MPH thesis, AAU, Ethiopia; 2015.

16. Belete M. Magnitude of risky sexual behaviors and its effect on sexually transmitted diseases among undergraduate students of Addis Ababa University in 2016. Unpublished MPH thesis, AAU, Ethiopia; 2016.

17. Abosetugn AE, Zergaw A, Tadesse H, Addisu Y. Correlations between risky sexual behavior and parental communication among youth in Dilla town, Gedeo zone, South Ethiopia. Biology and Medicine. 2015;7(5):1.

18. Kebede D, Alem A, Mitike G, Enquselassie F, Berhane F, Abebe Y, et al. Khat and alcohol use and risky sex behaviour among in-school and out-of-school youth in Ethiopia. BMC Public Health. 2005;5(1):109.

19. Cherie A, Berhane Y. Peer pressure is the prime driver of risky sexual behaviors among school adolescents in Addis Ababa. Ethiopia. World Journal of AIDS. 2012:2(03):159.

20. Alamrew Z, Bedimo M, Azage M. Risky sexual practices and associated factors for HIV/AIDS infection among private college students in Bahir Dar City. Northwest Ethiopia ISRN Public Health. 2013;2013

21. Dadi AF, Teklu FG. Risky sexual behavior and associated factors among grade 9-12 students in Humera secondary school, western zone of Tigray, NW Ethiopia, 2014. Science Journal of Public Health. 2014;2(5):410-6.

22. Desale AY, Argaw MD, Yalew AW. Prevalence and associated factors of risky sexual Behaviours among in-school youth in Lalibela town, north Wollo zone, Amhara regional sate. Ethiopia: A Cross-Sectional Study Design Science. 2016;4(1):57-64.

23. Fite AC, Cherie A. Risky sexual behavior and its determinants among orphan and vulnerable children in Addis Ababa. Ethiopia World Journal of AIDS. 2016:6(04):111

24. Girma D, Hailu G, Ayana M, Ketema K. Factors early sexual initiation among governmental preparatory school students, Addis Ababa. Ethiopia J Community Med Health Educ. 2015;5(333):2161-0711.1000333.

25. Gizaw A, Jara D, Ketema K. Risky sexual practice and associated factors among high school adolescent in Addis Ababa, Ethiopia, 2014. Fam Med Med Sci Res. 2014;3(141):2.

26. Kassa GM, Degu G, Yitayew M, Misganaw W, Muche M, Demelash T, et al. Risky sexual behaviors and associated factors among Jiga high school and preparatory school students, Amhara Region, Ethiopia. International scholarly research notices, vol. 2016, Article ID 4315729, p. 7, 2016. doi:10. 1155/2016/4315729

27. Mulu W, Yimer M, Abera B. Sexual behaviours and associated factors among students at Bahir Dar University: a cross sectional study. Reprod Health. 2014;11(1):84.

28. Tura G, Alemseged F, Dejene S. Risky sexual behavior and predisposing factors among students of Jimma University, Ethiopia. Ethiopian J Health Sci. 2012;22(3):170-80

29. Abebe M, Tsion A, Netsanet F. Living with parents and risky sexual behaviors among preparatory school students in Jimma zone, south west Ethiopia. Afr Health Sci. 2013;13(2):498-506.

30. Tadesse G, Yakob B. Risky sexual behaviors among female youth in Tiss Abay, a semi-urban area of the Amhara Region. Ethiopia PloS one. 2015; 10(3):e0119050

31. Tiruneh K, Wasie B, Gonzalez H. Sexual behavior and vulnerability to HIV infection among seasonal migrant laborers in Metema district, northwest Ethiopia: a cross-sectional study. BMC Public Health. 2015;15(1):122.

32. Bayissa D, Mebrahtu G, Bayisa G, Mekuanint Y. Assessment of Early Sexual Initiation and Associated Factors among Ambo University Undergraduate Students, Ambo, Ethiopia. J Contracept Stud. 2016;1(2):7.

33. Procope-Beckles M. Global School Health Survey (GSHS) 2007 Tobago Report. Global School Health Survey (GSHS) 2007 Tobago Report: Ministerio de Salud, Tobago; 2007.

34. Wellings $K$, Collumbien M, Slaymaker $E$, Singh $S$, Hodges $Z$, Patel D, et al. Sexual behaviour in context: a global perspective. Lancet. 2006;368(9548):1706-28.

35. Romero-Estudillo E, González-Jiménez E, María C, Mesa-Franco M, GarcíaGarcía I. Gender-based differences in the high-risk sexual behaviours of young people aged 15-29 in Melilla (Spain): a cross-sectional study. BMC Public Health. 2014:14:745. Available at http://www.biomedcentral.com/ $1471-2458 / 14 / 745$

36. WHO. Alcohol use and sexual risk behaviour: a cross-cultural study in eight countries: World Health Organization; 2005.
37. Vagenas P, Lama JR, Ludford KT, Gonzales P, Sanchez J, Altice FL. A systematic review of alcohol use and sexual risk-taking in Latin America. Revista panamericana de salud publica. 2013;34(4):267-74.

38. Fearon $E$, Wiggins $R D$, Pettifor $A E$, Hargreaves JR. Is the sexual behaviour of young people in sub-Saharan Africa influenced by their peers? A systematic review. Soc Sci Med. 2015;146:62-74.

39. Bingenheimer JB, Asante $E$, Ahiadeke C. Peer influences on sexual activity among adolescents in Ghana. Stud Fam Plan. 2015;46(1):1-19.

40. Mattebo M, Tydén T, Häggström-Nordin E, Nilsson KW, Larsson M. Pornography consumption, sexual experiences, lifestyles, and self-rated health among male adolescents in Sweden. J Dev Behavioral Pediatrics. 2013;34(7):460-8.

41. Harkness EL, Mullan B, Blaszczynski A. Association between pornography use and sexual risk behaviors in adult consumers: a systematic review. Cyberpsychol, Behav, Soc Networking. 2015;18(2):59-71.

\section{Submit your next manuscript to BioMed Central and we will help you at every step:}

- We accept pre-submission inquiries

- Our selector tool helps you to find the most relevant journal

- We provide round the clock customer support

- Convenient online submission

- Thorough peer review

- Inclusion in PubMed and all major indexing services

- Maximum visibility for your research

Submit your manuscript at www.biomedcentral.com/submit
) Biomed Central 